Article

\title{
Immunochromatographic Detection of Myoglobin as a Specific Biomarker of Porcine Muscle Tissues in Meat Products
}

\author{
Elena A. Zvereva, Nadezhda A. Byzova, Olga D. Hendrickson, Demid S. Popravko, \\ Ksenia A. Belichenko, Boris B. Dzantiev $\mathbb{D}^{\mathbb{D}}$ and Anatoly V. Zherdev * $\mathbb{D}$
}

A.N. Bach Institute of Biochemistry, Research Center of Biotechnology of the Russian Academy of Sciences, Russian Academy of Sciences, Leninsky Prospect 33, 119071 Moscow, Russia; zverevaea@yandex.ru (E.A.Z.); nbyzova@inbi.ras.ru (N.A.B.); odhendrick@gmail.com (O.D.H.); dspopravko@mitht.ru (D.S.P.); ksuubelik@gmail.com (K.A.B.); dzantiev@inbi.ras.ru (B.B.D.)

* Correspondence: zherdev@inbi.ras.ru; Tel./Fax: +7-(495)-954-28-04

Received: 8 October 2020; Accepted: 21 October 2020; Published: 23 October 2020

\begin{abstract}
An immunochromatographic detection of myoglobin (MG) as a specific marker of porcine muscle tissue has been developed. The method is based on the sandwich lateral flow immunoassay (LFIA) with gold nanoparticles (AuNPs) as a label. The developed test system determines MG with a detection limit of $5 \mathrm{ng} \mathrm{mL}^{-1}$ within $15 \mathrm{~min}$. A specific determination of porcine MG and no cross-reactivity with MG from other tested mammals and bird species was demonstrated. The test system is able to detect pork additives, as low as $0.01 \%(w / w)$, in minced beef. A technique of MG extraction from muscle tissue has been proposed which allows for rapid and efficient MG extraction from meat samples (within $20 \mathrm{~min}$ ). The developed test system can serve as an effective means of controlling the authenticity and quality of meat products.
\end{abstract}

Keywords: myoglobin; lateral flow assay; colloidal gold; porcine meat

\section{Introduction}

The problem of quality and authenticity of food products has become extremely urgent in recent years, due to the expansion of technological capabilities of production, as well as an increase in counterfeiting of food, in particular meat products [1]. The presence of undeclared ingredients in food products can cause adverse effects on human health (e.g., allergic reactions and the risk of zoonotic diseases) and have serious ethical consequences (non-compliance with halal and kosher requirements). Pork is one of the most common type of meat consumed directly or in food products [2]. However, a segment of the population cannot eat pork-containing food products in accordance with strict religious commandments [3].

To control the presence of pork in food, effective analytical methods which enable rapid and accurate testing are needed. Manufacturing innovations and the improvement of processing technologies can prevent the identification of certain meat types in finished products using microstructural (histological) methods of analysis. Electrophoresis, various types of spectroscopy, and chromatography are usually used as confirmatory analytical methods and are implemented according to multistage protocols in esspecially equipped laboratories by qualified personnel [4-7].

Polymerase chain reaction assay and the enzyme-linked immunosorbent assay (ELISA) are the most widely used approaches for pork identification [8,9]. The main advantage of molecular genetic analysis methods is their high specificity. The stability of the DNA molecule allows for the differentiation of various animal species' meat in foodstuffs that have passed all stages of technological processing. However, heat treatment reduces the DNA yield, which can distort the data regarding 
the amount of meat identified in the finished product [10]. For the quantitative determination of pork in meat products, Soares et al. used a calibration curve obtained from preliminary analysis of chicken meat containing $0.1-25 \%(w / w)$ pork [9]. It should be noted that the combination of membrane immunochromatography with molecular genetic analysis enabled the determination of pork, as low as $0.01 \%$, in a meat mixture, which greatly simplified the process of testing. However, even in this case, a complex and time-consuming technique of sample preparation was required before analysis [11,12].

Immunochemical methods, in particular the ELISA and lateral flow immunoassay (LFIA), can be used for rapid detection in a large number of samples with high sensitivity and specificity. LFIA is based on the use of a multimembrane composite with preliminary immobilized specific reagents. The analytical procedure consists of immersing the test strip into the extract obtained from the food product and assessing the result after 10-20 $\mathrm{min}[13,14]$. An important stage of the LFIA developed for assessing the quality of raw and cooked meat products is the selection of a molecular marker, which can be of a protein or peptide nature. To identify pork, troponin I [15], porcine serum albumin [16], and porcine immunoglobulins $[17,18]$ were used as markers.

Myoglobin (MG) can be considered to be a relevant marker for the immunodetection of pork. This cytoplasmic hemoprotein has been expressed in skeletal muscles and cardiac myocytes and has demonstrated significant variability of amino acid sequences for different species $[19,20]$. Kotoura et al. used MG as a marker for the ELISA of beef content in meat products [21]. Chan et al. developed an immunochromatographic test system based on two clones of anti-MG antibodies with different specificities to detect the fresh, not heat-treated, meat of cetaceans [22]. The application of MG as a marker for pork and horsemeat detection by high-performance liquid chromatography has been described by Giaretta et al. [23] and Di Giuseppe et al. [24]. The obtained results confirm the efficiency of MG as a species marker for identifying the muscle tissue of different animal species. However, to our knowledge, the detection of MG for halal control using rapid immunoassay has not been described.

In this study, for the first time, an immunochromatographic test system for the rapid determination of pork in meat products using MG as a detectable biomarker was developed.

\section{Materials and Methods}

\subsection{Chemicals}

MG and monoclonal antibodies against MG (clones 4E2cc, 1B4, and 7C3) were purchased from HyTest Ltd. (Turku, Finland). Monoclonal antibodies against MG (clones MyoA6, MyoB1, MyoB12, MyoD4, MyoE4, MyoF5, MyoF7, MyoH9, and MyoH11) were obtained from the Russian Research Center of Molecular Diagnostics and Therapy (Moscow, Russia). Rabbit anti-mouse polyclonal antibodies (RAMI) were purchased from Imtek (Moscow, Russia). Streptavidin conjugated with horseradish peroxidase (STR-HRP), Triton X-100, Tween 20, 3,3',5,5'-tetramethylbenzidine (TMB), ethylenediaminetetraacetic acid (EDTA), sodium citrate, dimethyl sulfoxide (DMSO), and glycerol were purchased from Sigma Chemicals (St. Louis, MO, USA). D-biotin- $N$-hydroxysuccinimide ester, N-hydroxysuccinimide (NHS), and 1-hydrochloride-ethyl-3-(3-dimethylaminopropyl) carbodiimide (EDC) were obtained from ICN Biomedicals (Irvine, CA, USA). All other chemicals (salts and solvents of analytical grade) were from Khimmed (Moscow, Russia). The ELISA was performed in transparent Costar 9018 96-well polystyrene microplates (Corning Costar, Tewksbury, MA, USA).

\subsection{Determination of the Immune Interactions' Constants}

The equilibrium and kinetic constants of the interaction between MG and specific antibodies were measured using the Biacore $X$ biosensor (Biacore AB, Uppsala, Sweden). The surface of the CM5 chip, modified with carboxymethylated dextran (Biacore AB, Uppsala, Sweden), was activated by passing a mixture of aqueous solutions of EDC and NHS at concentrations of 0.1 and $0.4 \mathrm{M}$, respectively. The immobilization of MG on the surface of the chip was carried out, according to the standard procedure [25]. For this purpose, an MG solution at a concentration of $70 \mu \mathrm{g} \mathrm{mL} \mathrm{L}^{-1}$ in $10 \mathrm{mM}$ Na-citrate 
buffer, $\mathrm{pH}$ 5.0, was used. Then, the following reagents were sequentially passed through the cell: anti-MG antibodies at a concentration of 4-400 nM in a buffer containing $10 \mathrm{mM} \mathrm{HEPES,} 150 \mathrm{mM} \mathrm{NaCl}$, $3 \mathrm{mM}$ EDTA, and $0.005 \%$ Tween 20, pH 7.4 (HBS-EP); HBS-EP; and a regenerating reagent $(100 \mathrm{mM}$ glycine- $\mathrm{HCl}, \mathrm{pH} 2.0)$. For each concentration of antibodies, the registration of immunochemical interactions was carried out in triplicate. For control measurements, the same protocol was used, with the exception of MG immobilization. An approximation of concentration dependences and a calculation of equilibrium and kinetic constants were performed using the BIA evaluation program "1:1 (Langmuir) binding" (Biacore AB, Uppsala, Sweden).

\subsection{Biotinylation of Antibodies}

Anti-MG monoclonal antibodies were dialyzed against a $50 \mathrm{mM}$ phosphate buffer containing $0.1 \mathrm{M} \mathrm{NaCl}, \mathrm{pH} 7.4$ (PBS), by a centrifugation at 10,000 $\mathrm{g}$ for $15 \mathrm{~min}$ using centrifuge tubes with cellulose acetate filters (Corning Costar Spin-X, Merck Millipore, Burlington, MA, USA). The covalent binding of biotin to antibodies was carried out at a molar ratio of 10:1, in accordance with the technique described by Bayer and Wilchek [26]. For this, a solution of biotin- $N$-hydroxysuccinimide ether in DMSO $\left(25 \mu \mathrm{L}, 3.1 \mathrm{mg} \mathrm{mL}^{-1}\right)$ was added to antibody solutions $\left(0.5 \mathrm{~mL}, 6.8 \mathrm{mg} \mathrm{mL}^{-1}\right)$. The reaction mixtures were incubated at room temperature for $2 \mathrm{~h}$. Biotinylated antibodies were dialyzed against PBS, as described above.

\subsection{Sandwich Enzyme Llinked Immunosorbent Assay (ELISA)}

A solution $(100 \mu \mathrm{L})$ of anti-MG monoclonal antibodies $\left(2 \mu \mathrm{g} \mathrm{mL}^{-1}\right)$ in PBS was immobilized in the microplate wells for $16 \mathrm{~h}$, at $4{ }^{\circ} \mathrm{C}$. Then, the microplate was washed four times with PBS with $0.05 \%$ Triton X-100 (PBST). After that, $100 \mu \mathrm{L}$ of MG solutions (ranging in concentration from $5 \mu \mathrm{g}$ $\mathrm{mL}^{-1}$ to $0.1 \mathrm{ng} \mathrm{mL} \mathrm{m}^{-1}$ ) in PBST was added to the wells and incubated for $1 \mathrm{~h}$, at $37^{\circ} \mathrm{C}$. The plate was washed four times with PBST, and $100 \mu \mathrm{L}$ of biotinylated antibodies $\left(2 \mu \mathrm{g} \mathrm{mL}{ }^{-1}\right)$ was added to the wells and incubated for $1 \mathrm{~h}$, at $37^{\circ} \mathrm{C}$. After washing, $100 \mu \mathrm{L}$ of STR-HRP (diluted 1:5000 with PBST) was added to the wells and incubated for $1 \mathrm{~h}$, at $37^{\circ} \mathrm{C}$. After the microplate was washed four times with PBST and one time with distilled water, the peroxidase activity was determined. For this purpose, $100 \mu \mathrm{L}$ of $0.42 \mathrm{mM}$ TMB solution in $0.1 \mathrm{M} \mathrm{Na}$-citrate buffer, $\mathrm{pH} 4.0$, with $1.8 \mathrm{mM} \mathrm{H}_{2} \mathrm{O}_{2}$, was added to the wells of the microplate and incubated for $15 \mathrm{~min}$ at room temperature. The reaction was stopped by the addition of $50 \mu \mathrm{L}$ of $1 \mathrm{M} \mathrm{H}_{2} \mathrm{SO}_{4}$ per well. The optical density (OD) of the reaction product was measured at $450 \mathrm{~nm}$ with a Zenyth 3100 microplate photometer (Anthos Labtec Instruments, Wals, Austria).

\subsection{Synthesis and Characterization of Gold Nanoparticles (AuNPs)}

Gold nanoparticles (AuNPs) were prepared, as described by Frens [27]. Briefly, $0.5 \mathrm{~mL}$ of a 1\% solution of chloroauric acid was added to $48.75 \mathrm{~mL}$ of deionized water and brought to a boil. After that, $0.75 \mathrm{~mL}$ of $1 \%$ sodium citrate solution was added while stirring. The mixture was boiled for $25 \mathrm{~min}$, and then cooled. The obtained AuNPs were stored at $4{ }^{\circ} \mathrm{C}$.

Transmission electron microscopy (TEM) was applied to analyze the dimensional characteristics of nanoparticles. The prepared AuNPs were dropped onto Formvar film-coated grids ( 300 mesh) and analyzed on a JEM-100C microscope (JEOL, Tokyo, Japan). Microphotographs were obtained at a voltage of $80 \mathrm{kV}$ and 66,000-100,000 zoom. The Image Tool 3.0 program (University of Texas Health Science Center, San Antonio, TX, USA) was used to analyze digital images.

\subsection{Immobilization of Antibodies on AuNPs}

The preparation of antibody AuNP conjugates was carried, out as described by [28]. Before conjugation, antibodies were dialyzed against $10 \mathrm{mM}$ Tris- $\mathrm{HCl}$ buffer, $\mathrm{pH} 8.5$, for $2 \mathrm{~h}$, at $4{ }^{\circ} \mathrm{C}$. The $\mathrm{pH}$ of the AuNP solution was adjusted to 8.5-9.0 with $0.2 \mathrm{M} \mathrm{K}_{2} \mathrm{CO}_{3}$, and then the antibodies 
were added with a concentration of $20 \mu \mathrm{g} \mathrm{mL}^{-1}$ for $4 \mathrm{E} 2 \mathrm{cc}$ and $7 \mathrm{C} 3$ clones; $10 \mu \mathrm{g} \mathrm{mL} \mathrm{L}^{-1}$ for $1 \mathrm{~B} 4$ clone; and $8 \mu \mathrm{g} \mathrm{mL}^{-1}$ for MyoA6, MyoD4, MyoE4, MyoF5, and MyoH9 clones.

The resultant mixtures were stirred for $45 \mathrm{~min}$ at room temperature, followed by the addition of BSA to a final concentration of $0.25 \%$. Antibody AuNPs conjugates were separated from unreacted antibodies by centrifugation at $13,400 \times \mathrm{g}$ for $15 \mathrm{~min}$, at $4{ }^{\circ} \mathrm{C}$. After the removal of the supernatant, the residues were resuspended in a $10 \mathrm{mM}$ Tris buffer containing $1 \% \mathrm{BSA}, 1 \%$ sucrose, and $0.05 \%$ sodium azide, $\mathrm{pH} 8.5$ (TBSA), and stored at $4{ }^{\circ} \mathrm{C}$.

\subsection{Production of Immunochromatographic Tests}

A CNPC-SS12 working membrane with a $15 \mu \mathrm{m}$ pore size, a GFB-R4 sample membrane, an AP045 adsorption membrane, and a PT-R7 fiberglass membrane (Advanced Microdevices, Ambala Cantt, India) were used to compose test strips. The test zone of the working membrane was formed by anti-MG antibodies (2.0 mg mL ${ }^{-1}$ in PBS), and the control zone was formed by RAMI $\left(0.5 \mathrm{mg} \mathrm{mL}^{-1}\right.$ in PBS). Reagents were applied onto membranes with an Iso-Flow automatic dispenser (Imagene Technology, Hanover, NH, USA) at a rate of $0.1 \mu \mathrm{L}$ per mm of the membrane. Antibody AuNPs conjugates were manually applied onto a fiberglass membrane in a dilution corresponding to OD520 $=8.0$ in TBSA containing $0.05 \%$ Tween 20. The loading of antibody-AuNPs conjugates was $16 \mu \mathrm{L}$ per $1 \mathrm{~cm}$ of the membrane. All membranes with the immobilized reagents were dried at room temperature for at least $20 \mathrm{~h}$, and then fixed on a plastic pad.

\subsection{Sample Preparation Before the Lateral Flow Immunoassay (LFIA)}

Samples of raw meat, including beef, pork, lamb, and poultry (chicken and turkey), as well as assorted meat-based dumplings, were purchased at local supermarkets. Beef and pork-based cooked sausages with a confirmed composition were produced at the factory for manufacturing of meat products at the Gorbatov Federal Research Center for Food Systems of the Russian Academy of Sciences. All raw and cooked meat products were minced. A number of raw meat mixtures were obtained from minced raw meat, namely, beef containing $10,1,0.1$, and $0.01 \%(w / w)$ pork. The extraction was carried out using the following techniques:

1. A total of $100 \mathrm{mg}$ of raw or cooked minced meat is vigorously mixed with $2 \mathrm{~mL}$ of PBS, containing $0.1 \%$ Triton $\mathrm{X}-100$, and $0.5 \mathrm{M} \mathrm{KCl}$ (an extraction buffer), for $10 \mathrm{~min}$. The mixtures are centrifuged for $5 \mathrm{~min}$ at $5000 \times \mathrm{g}$ at room temperature. The obtained supernatants are incubated for $3 \mathrm{~min}$ at $100{ }^{\circ} \mathrm{C}$. Then, the samples are centrifuged for $5 \mathrm{~min}$ at $7000 \times g$, and supernatants are used for the LFIA [29].

2. A total of $250 \mathrm{mg}$ of raw or cooked minced meat is vigorously mixed with $5 \mathrm{~mL}$ of the extraction buffer for $30 \mathrm{~min}$, and then sonicates in an ultrasound bath for $30 \mathrm{~min}$. Mixtures are centrifuged for $10 \mathrm{~min}$ at $5000 \times \mathrm{g}$, and the obtained supernatants are used for the LFIA.

3. A total of $150 \mathrm{mg}$ of raw or cooked minced meat is vigorously mixed with $5 \mathrm{~mL}$ of PBST for $15 \mathrm{~min}$. The obtained mixtures are used for the LFIA.

4. A total of $150 \mathrm{mg}$ of raw or cooked minced meat is vigorously mixed with $5 \mathrm{~mL}$ of PBST for $15 \mathrm{~min}$. Mixtures are centrifuged for $5 \mathrm{~min}$ at $5000 \times g$, and the obtained supernatants are used for the LFIA.

\subsection{LFIA of Myoglobin (MG)}

Solutions of MG in PBST (a total volume of $100 \mu \mathrm{L}$ ), in concentration ranges of $1000-1 \mathrm{ng} \mathrm{mL}^{-1}$, were added to microplate wells. Test strips were immersed in the solutions and incubated for $15 \mathrm{~min}$ at room temperature. For determination of $\mathrm{MG}$ in raw and cooked meat, the corresponding extracts were added to microplate wells. All the measurements were performed in triplicate for statistical processing. The resultant strips were scanned using a flatbed scanner (CanoScan LiDE 90, Canon, Tokyo, Japan) with a resolution of $600 \mathrm{dpi}$ without applying modes for contrast or color correction. 
The TotalLab software package (TotalLab, Newcastle upon Tyne, UK, totallab.com) was used to process test strip images.

Linear approximations of the dependence of bands' color intensity on MG concentrations were constructed. The cutoff value (detection limit) of the LFIA was interpreted as the minimum MG concentration causing a reliable coloration in the test zone.

\section{Results and Discussion}

\subsection{Characterization of Monoclonal Antibodies by the ELISA}

The quantitative characterization of the interaction of MG with specific antibodies was carried out using a flow-through biosensor system, Biacore X, based on the registration of a surface plasmon resonance. Kinetic curves of association and dissociation processes of binary antibody-MG complexes at different concentrations of antibodies were obtained. On the basis of the experimental data, the corresponding kinetic $\left(\mathrm{k}_{\mathrm{a}}, \mathrm{k}_{\mathrm{d}}\right)$ and equilibrium $\left(\mathrm{K}_{\mathrm{A}}, \mathrm{K}_{\mathrm{D}}\right)$ constants of association and dissociation of antibody-MG complexes were calculated (Table 1).

Table 1. Analytical parameters of association and dissociation of antibody-myoglobin (MG) complexes.

\begin{tabular}{|c|c|c|c|c|c|}
\hline Clone & $\begin{array}{c}k_{a \prime} \\
\mathbf{M}^{-1} \times c^{-1}\end{array}$ & $\begin{array}{l}k_{d}, \\
\mathrm{c}^{-1}\end{array}$ & $\begin{array}{r}K_{A}, \\
\mathbf{M}^{-1}\end{array}$ & $\begin{array}{c}K_{D \prime} \\
\mathbf{M}\end{array}$ & $x^{2}$ \\
\hline 1B4 & $(2.0 \pm 0.5) \times 10^{5}$ & $(7.1 \pm 1.6) \times 10^{-5}$ & $(3.6 \pm 1.0) \times 10^{9}$ & $(4.7 \pm 1.6) \times 10^{-10}$ & 0.104 \\
\hline $4 \mathrm{E} 2 \mathrm{cc}$ & $(2.4 \pm 0.6) \times 10^{5}$ & $(5.1 \pm 1.7) \times 10^{-5}$ & $(7.6 \pm 3.2) \times 10^{9}$ & $(2.9 \pm 1.1) \times 10^{-10}$ & 0.842 \\
\hline $7 C 3$ & $(6.5 \pm 3.4) \times 10^{5}$ & $(3.2 \pm 0.8) \times 10^{-4}$ & $(2.8 \pm 1.0) \times 10^{9}$ & $(1.8 \pm 1.3) \times 10^{-9}$ & 0.158 \\
\hline MyoA6 & $(6.3 \pm 1.4) \times 10^{4}$ & $(2.8 \pm 0.1) \times 10^{-4}$ & $(2.2 \pm 0.5) \times 10^{8}$ & $(5.9 \pm 1.6) \times 10^{-9}$ & 0.196 \\
\hline MyoB1 & $(5.0 \pm 1.2) \times 10^{4}$ & $(3.6 \pm 0.5) \times 10^{-3}$ & $(1.4 \pm 0.3) \times 10^{7}$ & $(9.6 \pm 3.4) \times 10^{-8}$ & 0.227 \\
\hline MyoB12 & $(3.7 \pm 0.8) \times 10^{4}$ & $(3.6 \pm 0.5) \times 10^{-3}$ & $(7.1 \pm 1.6) \times 10^{6}$ & $(1.8 \pm 0.3) \times 10^{-7}$ & 0.122 \\
\hline MyoD4 & $(1.2 \pm 0.3) \times 10^{5}$ & $(7.0 \pm 2.0) \times 10^{-5}$ & $(1.9 \pm 0.3) \times 10^{9}$ & $(6.2 \pm 1.3) \times 10^{-10}$ & 0.287 \\
\hline MyoE4 & $(1.5 \pm 0.2) \times 10^{5}$ & $(5.1 \pm 0.8) \times 10^{-4}$ & $(3.4 \pm 0.7) \times 10^{8}$ & $(3.9 \pm 1.0) \times 10^{-9}$ & 0.124 \\
\hline MyoF5 & $(1.9 \pm 0.4) \times 10^{5}$ & $(6.2 \pm 2.1) \times 10^{-5}$ & $(6.1 \pm 3.7) \times 10^{9}$ & $(4.1 \pm 1.8) \times 10^{-10}$ & 0.085 \\
\hline MyoF7 & $(1.4 \pm 0.2) \times 10^{5}$ & $(1.2 \pm 0.3) \times 10^{-3}$ & $(1.8 \pm 0.7) \times 10^{8}$ & $(9.6 \pm 3.3) \times 10^{-9}$ & 0.138 \\
\hline MyoH9 & $(8.7 \pm 3.1) \times 10^{4}$ & $(4.6 \pm 1.5) \times 10^{-4}$ & $(3.2 \pm 1.4) \times 10^{8}$ & $(7.3 \pm 4.1) \times 10^{-9}$ & 0.265 \\
\hline MyoH11 & $(3.0 \pm 0.9) \times 10^{5}$ & $(8.3 \pm 0.6) \times 10^{-4}$ & $(3.9 \pm 1.5) \times 10^{8}$ & $(4.8 \pm 1.2) \times 10^{-9}$ & 0.091 \\
\hline
\end{tabular}

$k_{a}$, kinetic association constant; $k_{d}$, kinetic dissociation constant; $K_{A}$, equilibrium association constant; $K_{D}$, equilibrium dissociation constant.

It was demonstrated that the 1B4, 4E2cc, MyoD4, and MyoF5 clones of antibodies possessed the highest affinity $\left(K_{D}\right.$ values varied in the range 2.9-6.2 $\left.\times 10^{-10} \mathrm{M}\right)$. The 7C3, MyoA6, MyoE4, MyoF7, $\mathrm{MyoH} 9$, and MyoH11 clones were characterized by an average affinity level ( $\mathrm{K}_{\mathrm{D}}$ values varied in the range 1.8-9.6 $\left.\times 10^{-9} \mathrm{M}\right)$. The MyoB1, MyoB12 clones had the lowest affinity properties $\left(\mathrm{K}_{\mathrm{D}}\right.$ were $9.6 \times 10^{-8} \mathrm{M}$ and $1.8 \times 10^{-7} \mathrm{M}$, respectively).

For both the ELISA and LFIA, a sandwich assay format was used, which was suitable for assessing the preservation of the protein native structure and commonly used for the detection of antigens having at least two epitopes on their surface [30]. To perform the ELISA, conjugates of monoclonal antibodies with biotin were synthesized, in accordance with the method described in Section 2.3. For all 12 antibody-biotin conjugates obtained, a reliable binding with MG immobilized in the wells of the microplate at a concentration of $2 \mu \mathrm{g} \mathrm{mL} \mathrm{L}^{-1}$ was confirmed, and therefore they were further used in the ELISA. Testing of the immune properties of antibodies and their conjugates with biotin in the ELISA allowed for assessment of the ability to form triple antibody-MG—-biotinylated antibody complexes, which was important for further development of the LFIA. On the basis of the results of this testing, combinations that did not lead to a reliable binding in the ELISA or provided it only at extremely high (>100 $\mathrm{ng} \mathrm{mL}^{-1}$ ) MG concentrations, were excluded. After this exclusion, only eight combinations were selected for further studies. The analytical parameters of the ELISA using these reagents are summarized in Table 2. 
Table 2. Analytical parameters of the enzyme-linked immunosorbent assay (ELISA) and lateral flow immunoassay (LFIA) of MG.

\begin{tabular}{|c|c|c|c|}
\hline $\begin{array}{l}\text { Immobilized/Biotinylated } \\
\text { (AuNPs-Labeled) Antibody }\end{array}$ & $\begin{array}{l}\text { Detection Limit in the } \\
\text { ELISA of } \mathrm{MG}, \mathrm{ng} \mathrm{mL}^{-1}\end{array}$ & $\begin{array}{l}\text { Detection Limit in the } \\
\text { LFIA of } M G, \mathrm{ng} \mathrm{mL}^{-1}\end{array}$ & $\begin{array}{l}\text { Color Intensity of the } \\
\text { Analytical Zone, \% }\end{array}$ \\
\hline 7С3/MyoA6 & 9.2 & 5.0 & 100 \\
\hline 7C3/MyoD4 & 9.1 & 24.1 & 75 \\
\hline 7C3/MyoE4 & 12.8 & 35.6 & 35 \\
\hline 7C3/MyoF5 & 10.8 & 15.6 & 78 \\
\hline 7С3/MyoH9 & 13.7 & 10.2 & 79 \\
\hline 7C3/1B4 & 14.6 & 19.4 & 53 \\
\hline 7C3/4E2cc & 2.0 & 21.9 & $31 / 19$ \\
\hline $4 \mathrm{E} 2 \mathrm{cc} / 7 \mathrm{C} 3$ & 23.0 & 4.5 & $39 / 25$ \\
\hline
\end{tabular}

The probable reason for the absence or low intensity of the analytical signal for the remaining combinations is the coincidence or close location of epitopes on the surface of the MG molecule, which prevented the formation of a detectable antibody-antigen-antibody complex on the surface of the carrier. In addition, it should be noted that although antibodies selected for the formation of triple complexes were characterized by relatively high association constants (see Table 1), there was no strong correlation between their affinity and analytical characteristics of the ELISA. Because the experimental conditions (duration of steps and sequence of reagents' addition) were different during measurements of binding constants, the ELISA and LFIA, the combination that provided the maximum sensitivity in the ELISA (7C3/4E2cc-biotin), was not considered to be a priori optimal for this analysis. Hence, a comparative study was carried out for all eight combinations of antibodies indicated in Table 2. According to the study of Lo et al., the MG content in pork is approximately $2 \mathrm{mg} \mathrm{g}^{-1}$ [31]. Therefore, the ELISA characteristics of the selected pairs of antibodies indicate their suitability for the development of the LFIA with the, practically, demanded sensitivity.

\subsection{Obtaining and Characterization of Specific Reagents for the LFIA}

AuNPs were prepared by the reduction of chloroauric acid with sodium citrate, as described by Frens [27]. Characterization of AuNPs using TEM showed that the average diameter of spherical non-aggregated particles was $29.9 \pm 7.2 \mathrm{~nm}$ (in total, 55 nanoparticles were analyzed, the minimum and the maximum diameters were 19.2 and $40.3 \mathrm{~nm}$, respectively) and confirmed their suitability for the LFIA [32]. An image of AuNPs is presented in Figure 1A.

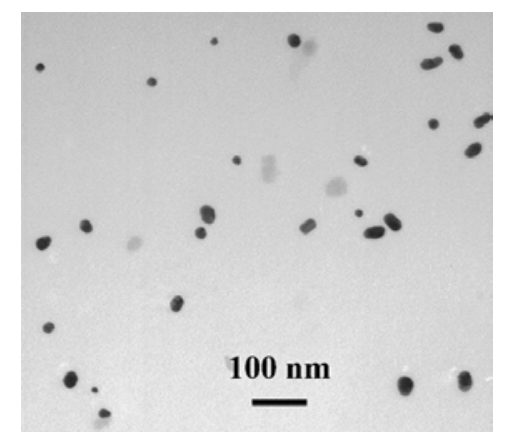

(A)

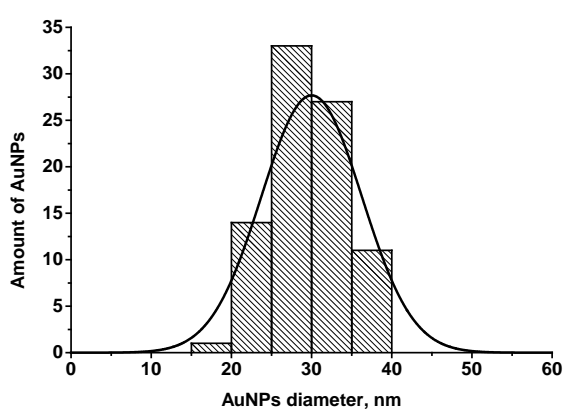

(B)

Figure 1. (A) Image of gold nanoparticles (AuNPs) obtained by transmission electron microscopy (TEM); (B) Histogram of particle size distribution.

Clones 4E2cc, 7C3, 1B4, MyoA6, MyoD4, MyoE4, MyoF5, and MyoH9 of monoclonal antibodies that were selected according to the results of the ELISA were conjugated to AuNPs. The selection of conjugation conditions was carried out on the basis of photometric data reflecting AuNPs' aggregation 
after the addition of $10 \%$ sodium chloride. As an example, the flocculation curve for the MyoA6 clone of antibodies is demonstrated in Figure 2.

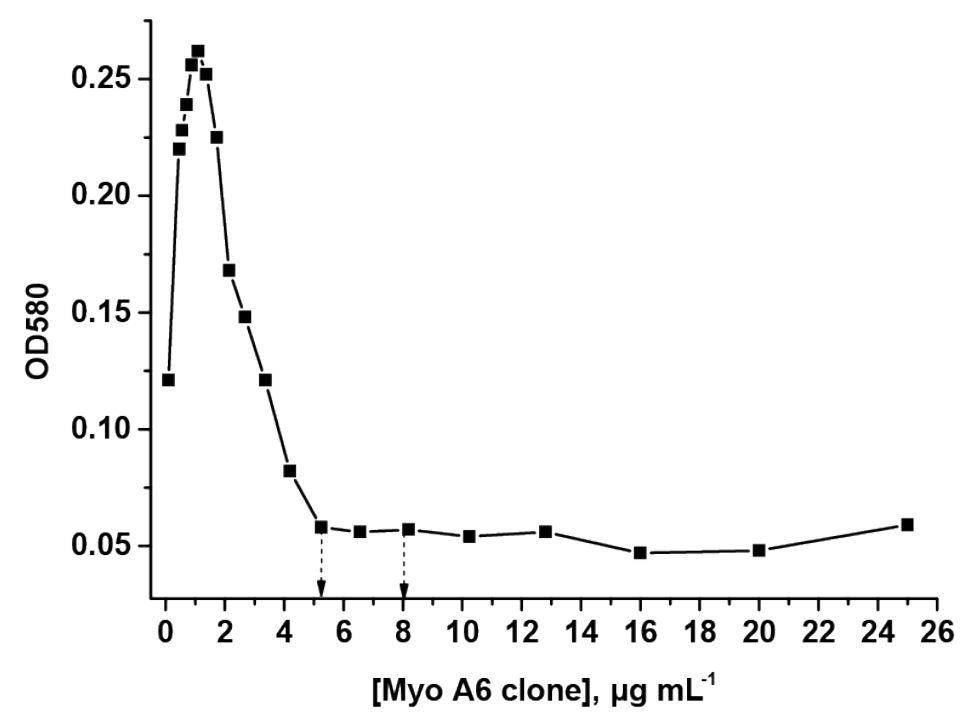

Figure 2. Flocculation curve for the MyoA6 clone of monoclonal antibodies. The flocculation point and a concentration of antibodies selected for the conjugation are indicated by arrows (5.2 and $8 \mu \mathrm{g} \mathrm{mL}{ }^{-1}$, respectively).

The obtained concentration dependences are characterized by an initial increase in OD, followed by a decline, and reached a plateau at a concentration of antibodies sufficient for a complete monolayer coating of a particle with antibodies (flocculation point). As recommended by Hermanson [33], the concentrations of antibodies were $10-20 \%$ higher than those corresponding to flocculation points, and therefore the surface of AuNPs were stabilized with the protein and the formation of aggregates was prevented. Therefore, for conjugation, $4 \mathrm{E} 2 \mathrm{cc}$ and $7 \mathrm{C} 3$ clones of antibodies were used at a concentration of $20 \mu \mathrm{g} \mathrm{mL}^{-1}$; clone 1B4 of antibodies was used at a concentration of $10 \mu \mathrm{g} \mathrm{mL} \mathrm{L}^{-1}$; and MyoA6, MyoD4, MyoE4, MyoF5, and MyoH9 clones of antibodies were used at a concentration of $8 \mu \mathrm{g} \mathrm{mL}{ }^{-1}$. The excess of unreacted antibodies was removed during the precipitation of the conjugates.

\subsection{Development of the LFIA of MG}

As working, sample, and adsorption membranes, a nitrocellulose CNPC-SS12 membrane with a $15 \mu \mathrm{m}$ pore size, a GFB-R4 membrane, and AP045 membranes were used, which proved to be effective in the analysis of meat extracts described in our previous study [34]. To form the control zone of the test strip, RAMI at a concentration of $0.5 \mathrm{mg} \mathrm{mL}^{-1}$ was applied. To determine the optimal working combination of the immunoreagents, test strips of different compositions were prepared. Thus, antibodies of 4E2cc and 7C3 clones were immobilized in the analytical zones of the strips, while 4E2cc, 7C3, 1B4, MyoA6, MyoD4, MyoE4, MyoF5, and MyoH9 clones labeled by AuNPs were applied onto fiberglass membranes. The results presented in Table 2 indicate that the maximum color intensity is observed when using the 7C3/AuNPs-MyoA6 pair. It was shown that the maximum assay sensitivity and the highest analytical signal amplitude were reached at a concentration for 7C3 clone of $2.0 \mathrm{mg} \mathrm{mL}^{-1}$. A further increase in the amount of 7C3 antibodies immobilized in the analytical zone did not significantly affect the signal intensity. The AuNPs-MyoA6 conjugate was applied onto a fiberglass membrane at a concentration that corresponded to OD520 $=8.0$ with $16 \mu \mathrm{L} \mathrm{cm}^{-1}$ loading, which ensured an intense coloration of the analytical band and the absence of nonspecific signal. The LFIA duration was $15 \mathrm{~min}$ because this time was shown to be sufficient to complete the movement of labeled antibodies along the test strip. Although the formation of colored bands was 
observed within 5-10 min after the immersion of the strip into the tested sample, this time was not enough to obtain highly reproducible quantitative results.

A calibration curve obtained under optimized conditions of the LFIA of MG using a 7C3/AuNPs-MyoA6 pair is shown in Figure 3. The developed test system is characterized by a MG detection limit of $5 \mathrm{ng} \mathrm{mL}-1$. The working range of detectable concentrations is $14-210 \mathrm{ng} \mathrm{mL}^{-1}$. Relative standard deviation (RSD) of the measured signal intensity was not more than $12 \%$.

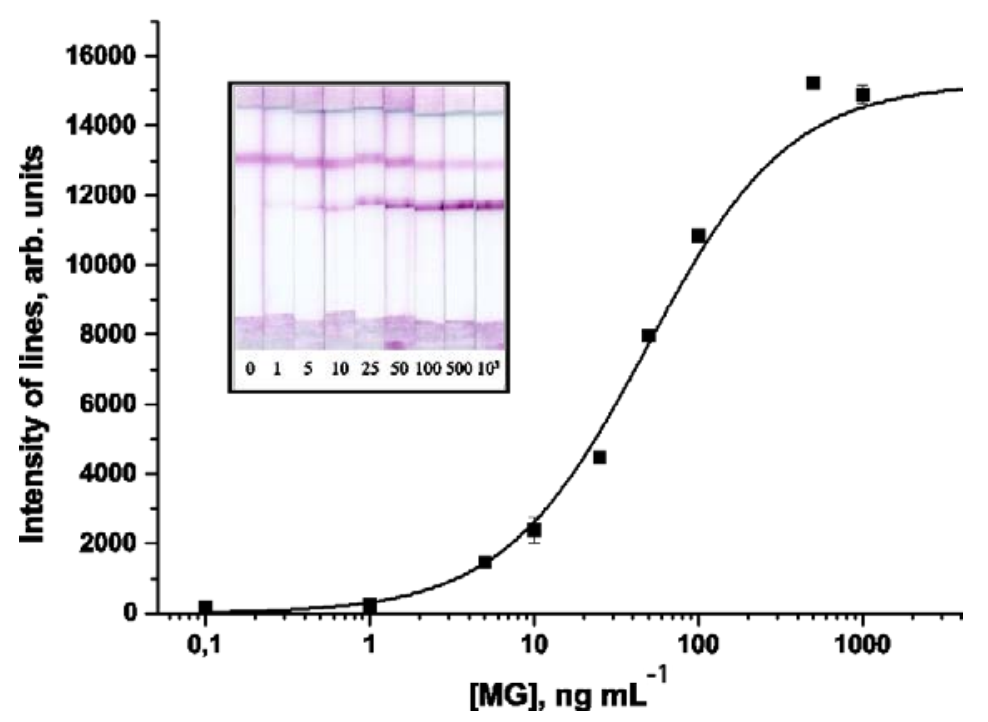

Figure 3. Calibration curve for MG in the sandwich-format LFIA.

\subsection{LFIA of Meat Samples}

A series of test strips were prepared, and immunochromatographic detection of MG in standard solutions, as well as in extracts obtained from meat samples of various mammals and bird species, were carried out. It is known that matrix components in the tested sample can affect the assay results. The efficiency of MG extraction from tissues is also of great importance because MG is found mainly in the form of complexes with other muscle proteins, which can cause shielding of its epitopes and prevent reliable determination of its content. Because MG is a salt-soluble protein [25], several sample preparation techniques based on MG extraction with PBS were developed and compared. To increase the completeness of the extraction, various concentrations of Triton X-100 were added to the extraction medium. It was demonstrated that the maximum amount of MG was obtained by the extraction with PBST for $15 \mathrm{~min}$, followed by centrifugation of the extract at $5000 \times \mathrm{g}$ for $5 \mathrm{~min}$ (Method No. 4 in Table 3). This procedure of sample preparation is simple and rapid because no special expensive equipment is required for its implementation and the total extraction time does not exceed $20 \mathrm{~min}$.

Table 3. MG content revealed by the LFIA after different sample preparation procedures.

\begin{tabular}{ccc}
\hline Method No. & Sample Preparation Procedure & MG, $\mathbf{~ m g ~ g}^{-\mathbf{1}}$ of Pork \\
\hline 1 & $\begin{array}{c}\text { Extraction with PBS, containing } 0.1 \% \text { Triton X-100 and } 0.5 \mathrm{M} \mathrm{KCl}, \\
\text { followed by an incubation at } 100{ }^{\circ} \mathrm{C} \text { and centrifugation for } 5 \mathrm{~min} \text { at } \\
7000 \times g\end{array}$ & $0.03 \pm 0.01$ \\
\hline 2 & $\begin{array}{c}\text { Extraction with PBS, containing } 0.1 \% \text { Triton X-100 and } 0.5 \mathrm{M} \mathrm{KCl}, \\
\text { followed by a sonication and centrifugation for } 10 \mathrm{~min} \text { at } 5000 \times g\end{array}$ & $0.25 \pm 0.02$ \\
\hline 3 & Extraction with PBST & $0.13 \pm 0.03$ \\
\hline 4 & Extraction with PBST followed by a centrifugation for 5 min at $5000 \times g$ & $0.40 \pm 0.03$ \\
\hline
\end{tabular}


Studies on the specificity of the developed test system showed that it could specifically detect MG isolated only from pork samples (Figure 4). There was no cross-reactivity with extracts obtained from meat of other mammals (beef and lamb) or poultry (chicken and turkey).

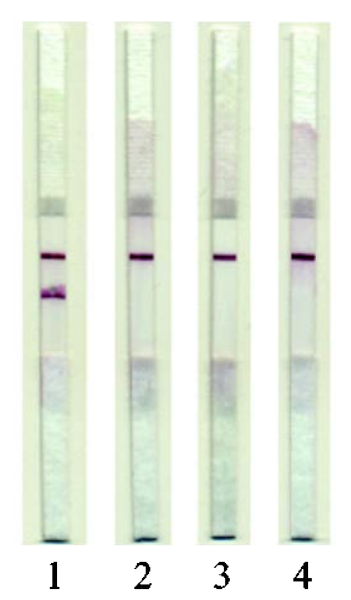

Figure 4. Testing of the LFIA specificity. Images of test strips after the LFIA was performed. (1) On pork extracts; (2), On beef extracts; (3) On lamb extracts; (4) On chicken extracts.

\subsection{LFIA of Raw Meat}

The developed test system was used to estimate the content of pork meat ingredient in raw meat mixtures and cooked meat products. To reveal the assay sensitivity, the extracts from model meat mixtures consisting of minced beef containing $10,1,0.1$, and $0.01 \%(w / w)$ of pork were analyzed. It was shown that the developed test system could reliably detect pork ingredient, as low as $0.01 \%$, in beef (Figure 5). High reproducibility of the LFIA results was demonstrated; the RSD of the measured signal intensity was not more than $14 \%$.

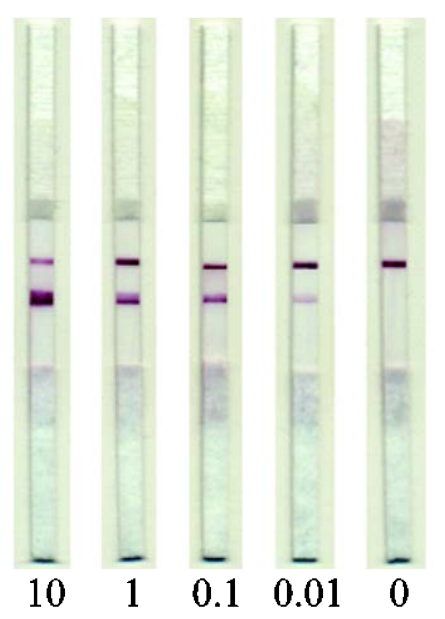

Figure 5. Images of test strips after the LFIA performed on meat extracts. The numbers indicate the pork meat content $(\%, w / w)$.

Thus, the developed test system is comparable in sensitivity to the previously reported immunoassay-based methods for porcine meat detection and surpasses them in sample preparation rapidity (Table 4). 
Table 4. Comparison of methods for porcine meat detection.

\begin{tabular}{cccccc}
\hline Method & Analyte & Detection Limit, $\%$ & Extraction Time, min & Time of Analysis, min & Reference \\
\hline ELISA & IgG & $0.01 / 0.1$ & $>40$ & $>700 / 45$ & {$[8]$} \\
Immunosensor & IgG & 0.01 & $>40$ & 20 & {$[8]$} \\
PCR & DNA & 5 & 235 & 80 & {$[9]$} \\
Real-time PCR & DNA & 0.1 & 235 & 28 & {$[9]$} \\
UPLC & Proteins profile & 5 & 40 & 30 & {$[23]$} \\
LFIA & DNA & 0.02 & $>60$ & 15 & {$[11]$} \\
LFIA & DNA & 0.01 & $>90$ & 5 & {$[12]$} \\
LFIA & PSA & 0.01 & 25 & 15 & {$[16]$} \\
LFIA & IgG & 0.1 & 65 & 15 & {$[18]$} \\
LFIA & MG & 0.01 & 20 & 15 & Present work \\
\hline
\end{tabular}

PSA $^{*}$, pig serum albumin.

\subsection{LFIA of Cooked Meat}

Several samples of sausages (cooked and cooked/smoked) and dumplings of different compositions were tested. Beef and pork-based cooked sausages with confirmed composition were produced at the factory for manufacturing of meat products of the V.M. Gorbatov Federal Research Center for Food Systems of the Russian Academy of Sciences. The results are presented in Figure 6.

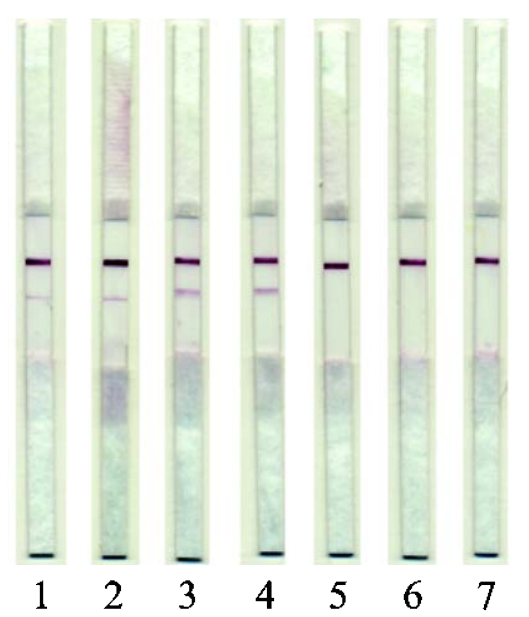

Figure 6. Images of test strips after the LFIA. (1) Beef/pork cooked sausages (2) Beef/pork cooked and smoked sausages; (3) Beef/pork dumplings; (4) Venison/pork dumplings; (5) Beef dumplings; (6) Lamb dumplings; (7) Chicken dumplings.

Experiments on the analysis of sausage, which included pork fat, showed that the test system does not give a signal in the presence of such an additive. Accordingly, its capabilities are focused only on options for the ad hoc addition of pork muscle tissue to meat products.

The obtained data indicated that the developed test system for identifying pork in raw-meat-based dumplings (Samples 3 and 4) and also in cooked sausages, passed all stages of the technological cycle (Samples 1 and 2).

\section{Conclusions}

The characterization of anti-MG monoclonal antibodies and their conjugates with biotin and AuNPs were carried out by the ELISA and LFIA. An optimal pair of immunoreagents was selected, for detecting MG in the sandwich-format LFIA with a sensitivity of $5 \mathrm{ng} / \mathrm{mL}$ within $15 \mathrm{~min}$. The test system specifically detects MG isolated from pork and demonstrates no cross-reactivity with MG of other species of mammals and birds. A simple and rapid technique for sample preparation is proposed that efficiently extracts MG from raw and cooked meat products. The developed LFIA can detect quantities of pork additives, as low as $0.01 \%$, in beef. The assay results can be monitored visually or 
using a photometric detector (scanner). The proposed test system is able to detect pork MG in food products that have passed all stages of the technological cycle.

The advantage of the developed test system over the existing approaches for porcine meat detection is the reduction in the assay duration (sample preparation + the LFIA step). This feature, and low demands for the common equipment used, determines the competitive potential of the given developments. Due to the rapidity and methodological simplicity, the proposed assay can be considered to be an efficient screening tool for identifying undeclared additives of porcine meat in meat products.

Author Contributions: Conceptualization, E.A.Z., A.V.Z., and B.B.D.; Methodology, E.A.Z.; Software, D.S.P.; Validation, O.D.H.; Formal analysis, N.A.B. and O.D.H.; Investigation, E.A.Z., N.A.B., K.A.B., and O.D.H.; Resources, A.V.Z.; Writing—original draft preparation, E.A.Z.; Writing—review and editing, A.V.Z.; Visualization, D.S.P.; Project administration, B.B.D.; Funding acquisition, A.V.Z. All authors have read and agreed to the published version of the manuscript.

Funding: This work was supported by the Russian Science Foundation (project no. 19-16-00108).

Acknowledgments: The authors are grateful to Academician I.M. Chernukha and N.L. Vostrikova (V.M. Gorbatov Federal Research Center for Food Systems) for preparation and providing cooked meat products of known composition, to P.G. Sveshnikov (Russian Research Center of Molecular Diagnostics and Therapy) for providing monoclonal antibodies against MG, and to S.M. Pridvorova (Research Center of Biotechnology) for supplying and processing TEM microphotographs.

Conflicts of Interest: The authors declare no conflict of interest.

\section{References}

1. Cavin, C.; Cottenet, G.; Cooper, K.M.; Zbinden, P. Meat vulnerabilities to economic food adulteration require new analytical solutions. CHIMIA Int. J. Chem. (Aarau) 2018, 72, 697-703. [CrossRef] [PubMed]

2. Zia, Q.; Alawami, M.; Mokhtar, N.F.K.; Mohd, R.; Nhari, H.R.; Hanish, I. Current analytical methods for porcine identification in meat and meat products. Food Chem. 2020, 324, 126664. [CrossRef] [PubMed]

3. Premanandh, J.; Bin Salem, S. Progress and challenges associated with Halal authentication of consumer packaged goods. J. Sci. Food Agric. 2017, 97, 4672-4678. [CrossRef] [PubMed]

4. Ballin, N.Z. Authentication of meat and meat products. Meat Sci. 2010, 86, 577-587. [CrossRef] [PubMed]

5. Chernukha, I.M.; Vostrikova, N.L.; Khvostov, D.V.; Zvereva, E.A.; Taranova, N.A.; Zherdev, A.V. Methods of identification of muscle tissue in meat products. prerequisites for creating a multi-level control system. Theory Pract. Meat Process. 2019, 4, 32-40. [CrossRef]

6. Al-Jowder, O.; Casuscelli, F.; Defernez, M.; Kemsley, E.K.; Wilson, R.H.; Colquhoun, I.J. High resolution NMR studies of meat composition and authenticity. In Magnetic Resonance in Food Science: A View to the Future, 1st ed.; Webb, G.A., Belton, P.S., Gil, A.M., Delgadillo, I., Eds.; Royal Society of Chemistry: Cambridge, UK, 2001; pp. 232-238.

7. Jakes, W.; Gerdova, A.; Defernez, M.; Watson, A.D.; McCallum, C.; Limer, E.; Colquhoun, IJ.; Williamson, D.C.; Kemsley, E.K. Authentication of beef versus horse meat using $60 \mathrm{MHz} 1 \mathrm{H}$ NMR spectroscopy. Food Chem. 2015, 175, 1-9. [CrossRef]

8. Mandli, J.; El Fatimi, I.; Seddaoui, N.; Amine, A. Enzyme immunoassay (ELISA/immunosensor) for a sensitive detection of pork adulteration in meat. Food Chem. 2018, 255, 380-389. [CrossRef]

9. Soares, S.; Amaral, J.S.; Oliveira, M.B.P.P.; Mafra, I. A SYBR Green real-time PCR assay to detect and quantify pork meat in processed poultry meat products. Meat Sci. 2013, 94, 115-120. [CrossRef]

10. Sentandreu, M.A.; Sentandreu, E. Authenticity of meat products: Tools against fraud. Food Res. Int. 2014, 60, 19-29. [CrossRef]

11. Magiati, M.; Myridaki, V.M.; Christopoulos, T.K.; Kalogianni, D.P. Lateral flow test for meat authentication with visual detection. Food Chem. 2019, 274, 803-807. [CrossRef]

12. Yin, R.; Sun, Y.; Wang, K.; Feng, N.; Zhang, H.; Xiao, M. Development of a PCR-based lateral flow strip assay for the simple, rapid, and accurate detection of pork in meat and meat products. Food Chem. 2020, 318, 126541. [CrossRef] [PubMed] 
13. Anfossi, L.; Di Nardo, F.; Cavalera, S.; Giovannoli, C.; Baggiani, C. Multiplex lateral flow immunoassay: An overview of strategies towards high-throughput point-of-need testing. Biosensors 2019, 9, 2. [CrossRef] [PubMed]

14. Dzantiev, B.B.; Byzova, N.A.; Urusov, A.E.; Zherdev, A.V. Immunochromatographic methods in food analysis. TrAC Trends Anal. Chem. 2014, 55, 81-93. [CrossRef]

15. Chen, F.C.; Hsieh, Y.-H.P. Porcine troponin I: A thermostable species marker protein. Meat Sci. 2002, 61, 55-60. [CrossRef]

16. Masiri, J.; Benoit, L.; Barrios-Lopez, B.; Thienes, C.; Meshgi, M.; Agapov, A.; Dobritsa, A.; Nadala, C.; Samadpour, M. Development and validation of a rapid test system for detection of pork meat and collagen residues. Meat Sci. 2016, 121, 397-402. [CrossRef] [PubMed]

17. Depamede, S.N. Development of a rapid immunodiagnostic test for pork components in raw beef and chicken meats: A preliminary study. Media Peternak. 2011, 34, 83-87. [CrossRef]

18. Kuswandi, B.; Gani, A.A.; Ahmad, M. Immuno strip test for detection of pork adulteration in cooked meatballs. Food Biosci. 2017, 19, 1-6. [CrossRef]

19. Joseph, P.; Suman, S.P.; Li, S.; Claus, J.R.; Fontaine, M.; Steinke, L. Primary structure of turkey myoglobin. Food Chem. 2011, 129, 175-178. [CrossRef]

20. Ragucci, S.; Russo, R.; Landi, N.; Valletta, M.; Chambery, A.; Esposito, S.; Raundrup, K.; Di Maro, A. Muskox myoglobin: Purification, characterization and kinetics studies compared with cattle and water buffalo myoglobins. J. Sci. Food Agric. 2019, 99, 6278-6286. [CrossRef]

21. Kotoura, S.; Murakami-Yamaguchi, Y.; Kizu, K.; Nakamura, M.; Fuchu, H.; Miake, K.; Sugiyama, M.; Narita, H. Establishment of a sandwich ELISA for the determination of beef content in processed foods by using monoclonal antibodies to myoglobin. Food Agric. Immunol. 2012, 23, 289-301. [CrossRef]

22. Chan, K.W.; Lo, C.; Chu, C.S.; Chin, L.T.; Wang, Y.T.; Yang, W.C. Development of a colloidal gold-based immunochromatographic test strip for detection of cetacean myoglobin. J. Vis. Exp. 2016, 113, e53433. [CrossRef]

23. Giaretta, N.; Di Giuseppe, A.M.A.; Lippert, M.; Parente, A.; Di Maro, A. Myoglobin as marker in meat adulteration: A UPLC method for determining the presence of pork meat in raw beef burger. Food Chem. 2013, 141, 1814-1820. [CrossRef] [PubMed]

24. Di Giuseppe, A.M.A.; Giarretta, N.; Lippert, M.; Severino, V.; Di Maro, A. An improved UPLC method for the detection of undeclared horse meat addition by using myoglobin as molecular marker. Food Chem. 2015, 169, 241-245. [CrossRef]

25. Biacore, A.B. Biacore X Handbook; Biacore AB: Uppsala, Sweden, 2001; p. 108.

26. Bayer, E.A.; Wilchek, M. Protein biotinylation. Methods Enzymol. 1990, 184, 138-160. [CrossRef]

27. Frens, G. Controlled nucleation for the regulation of the particle size in monodisperse gold suspensions. Nat. Phys. Sci. 1973, 241, 20-22. [CrossRef]

28. Zvereva, E.A.; Hendrickson, O.D.; Zherdev, A.V.; Dzantiev, B.B. Immunochromatographic tests for the detection of microcystin-LR toxin in water and fish samples. Anal. Methods 2020, 12, 392-400. [CrossRef]

29. Zvereva, E.A.; Kovalev, L.I.; Ivanov, A.V.; Kovaleva, M.A.; Zherdev, A.V.; Shishkin, S.S.; Lisitsyn, A.B.; Chernukha, I.M.; Dzantiev, B.B. Enzyme immunoassay and proteomic characterization of troponin I as a marker of mammalian muscle compounds in raw meat and some meat products. Meat Sci. 2015, 105, 46-52. [CrossRef]

30. Wild, D.G. Immunoassay Handbook: Theory and Applications of Ligand Binding, ELISA and Related Techniques, 4th ed.; Elsevier Science: Amsterdam, The Netherlands, 2013; 1036p.

31. Lo, C.; Chin, L.T.; Chu, C.S.; Wang, Y.T.; Chan, K.W.; Yang, W.C. Rapid immune colloidal gold strip for cetacean meat restraining illegal trade and consumption: Implications for conservation and public health. PLoS ONE 2013, 8, e60704. [CrossRef]

32. Safenkova, I.; Zherdev, A.; Dzantiev, B. Factors influencing the detection limit of the lateral-flow sandwich immunoassay: A case study with potato virus X. Anal. Bioanal. Chem. 2012, 403, 1595-1605. [CrossRef] 
33. Hermanson, G.T. Bioconjugate Techniques; Academic Press, Elsevier: Amsterdam, The Netherlands, 2008; 1200 .

34. Zvereva, E.A.; Zherdev, A.V.; Xu, C.; Dzantiev, B.B. Highly sensitive immunochromatographic assay for qualitative and quantitative control of beta-agonist salbutamol and its structural analogs in foods. Food Control 2018, 86, 50-58. [CrossRef]

Publisher's Note: MDPI stays neutral with regard to jurisdictional claims in published maps and institutional affiliations.

(C) 2020 by the authors. Licensee MDPI, Basel, Switzerland. This article is an open access article distributed under the terms and conditions of the Creative Commons Attribution (CC BY) license (http://creativecommons.org/licenses/by/4.0/). 